\title{
Can automated measures of lying time help assess lameness and leg lesions on tie-stall dairy farms?
}

\author{
Gemma L. Charlton ${ }^{\mathrm{a}, *}$, Veronique Bouffard ${ }^{\mathrm{b}, \mathrm{c}}$, Jenny Gibbons ${ }^{\mathrm{a}}$, Elsa Vasseur ${ }^{\mathrm{d}}$, \\ Derek B. Haley ${ }^{\mathrm{e}}$, Doris Pellerin ${ }^{\mathrm{b}}$, Jeffrey Rushen ${ }^{\mathrm{a}}$, Anne Marie de Passillé ${ }^{\mathrm{a}}$ \\ a Dairy Education and Research Centre, University of British Columbia, Agassiz, BC, Canada V0M 1A0 \\ b Department of Animal Science, Université Laval, Quebec, QC, Canada G1V OA6 \\ c Valacta Inc., Sainte-Anne-de-Bellevue, QC, Canada H9X 3R4 \\ d Organic Dairy Research Center, University of Guelph-Campus d'Alfred, Alfred, ON, Canada KOB 1AO \\ e Department of Population Medicine, University of Guelph, Guelph, ON, Canada N1G 2W1
}

\section{A R T I C L E I N F O}

\section{Article history:}

Accepted 9 February 2015

Available online 17 February 2015

\section{Keywords:}

Dairy cattle

Lameness

Hock lesion

Knee lesions

Lying time

Automated measures

\section{A B S T R A C T}

The time that dairy cows spend lying down is an important measure of their comfort and lameness and injuries to hocks and knees are associated with alterations in lying time. We examined whether automated measures of lying time could identify cows and farms with problems of lameness or leg lesions. Data were collected from 40 lactating Holstein dairy cows from each of 100 tie-stall farms. The occurrence of lameness, hock and knee injuries was recorded and lying times were recorded automatically using accelerometers. There was large variation between individual cows, and between farms in all measures of lying time. At the cow level, there was no relationship $(P>0.10)$ between being lame and daily duration of lying time. A lower daily duration of lying time was found among cows with hock injuries (mean $\pm \mathrm{SE}$ : non-injured $=12.79 \pm 0.06 \mathrm{~h}$, injured $=12.21 \pm 0.06 \mathrm{~h} ; P<0.001$ ) and cows with knee injuries (mean \pm SE: non-injured $=12.54 \pm 0.05 \mathrm{~h}$, injured $=12.25 \pm 0.06 \mathrm{~h}$; $P=0.04$ ) than those without lesions. The median daily duration of lying time on a farm was negatively correlated with the prevalence of lameness $\left(r_{p}=-0.27, P=0.006\right)$, of hock injuries $\left(r_{p}=-0.35, P=0.003\right)$ and of knee injuries $\left(r_{p}=-0.28, P=0.004\right)$. A canonical discriminant function with canonical coefficients of 0.63 for mean daily duration of lying down, and of 0.54 for mean bout frequency could correctly identify $72 \%$ of the farms that were above the median for percent of cows with hock or knee injuries or being lame (linear discriminant function: constant $=-95.10$, daily duration $=11.39$, bout frequency $=4.83$ ) and $68 \%$ of the farms below the median (linear discriminant function: constant $=-106.95$, daily duration $=11.92$, bout frequency $=5.30$ ) (Wilks Lambda test $P=0.002$ ). A criterion of a median lying time between $12 \mathrm{~h}$ and $13 \mathrm{~h}$ alone could identify over $60 \%$ of farms above or below the median for lameness, hock and knee lesion prevalence. Automated measures of lying time may be a useful animal-based measure to indicate farms with a high percentage of lame cows or cows with leg lesions.

(C) 2015 Elsevier B.V. All rights reserved.

\footnotetext{
* Corresponding author.

E-mail address: gemmalcharlton@yahoo.co.uk(G.L. Charlton).
}

\section{Introduction}

Lameness is widely recognized as a significant welfare problem for cows in free-stalls (von Keyserlingk et al., 2012) and tie-stalls (Bielfeldt et al., 2005; Cramer et al., 
2009) caused by numerous factors including lying comfort, cubicle design, flooring type, time away from the pen for milking, body condition score (BCS), and nutrition (Dippel et al., 2009; Espejo and Endres, 2007). Hock and knee lesions are also common in cattle kept in tie-stalls (Zurbrigg et al., 2005), are more common among lame cattle (Zaffino Heyerhoff et al., 2014) and are also a common welfare concern (Rushen et al., 2008; von Keyserlingk et al., 2009). As lesions are a direct result of tissue damage, and lameness can be a consequence of pain and hoof lesions, measuring the prevalence of lameness and injuries is an important aspect of the welfare assessment of dairy farms (e.g. Whay et al., 2003). However, direct or video-based observations of animal behavior are time consuming, and it can be particularly challenging to detect lameness in tie-stalls, where cows are often unaccustomed to walking freely. Many cows are milked in their stall and are rarely given the opportunity to exercise, even in summer, which reduces the chances of detecting behavioral signs of lameness in tie-stalls. Automated methods of detecting lame or injured cows and assessing prevalence on tie-stall farms would be useful.

Lying down and resting are high-priority activities for dairy cows (Jensen et al., 2005; Munksgaard et al., 2005) and previous research has identified complex links between time lying with lameness and leg lesions in dairy cows. Short lying times are a risk factor for lameness (Bell et al., 2009), lame cows spend more time lying down than non-lame cows (Chapinal et al., 2009; Ito et al., 2010; Blackie et al., 2011) while cows with knee lesions spend less time lying down than those without (Rushen et al., 2007). Lack of comfort in stalls has been identified as a risk factor for lameness (Dippel et al., 2009), knee lesions (Rushen et al., 2007) and hock lesions (Weary and Taszkun, 2000) resulting in reduced lying time in tie-stall housed cows (Haley et al., 2001). Together these results suggest that changes in lying times may be a means of identifying either cows or farms at risk of a high prevalence of lameness or leg lesions.

Taking behavioral measures of animal welfare, such as lying behavior on-farm is time consuming and labor intensive, which has led to interest in automated behavioral monitoring (Rushen et al., 2012). With recent advances in the use of accelerometers, the lying behavior of individual animals can now be recorded automatically on commercial farms (Ito et al., 2009). For cows in free-stall herds, automatically measuring lying time is useful to identify lame cows (Chapinal et al., 2009; Ito et al., 2010), however, this has not yet been tested on tie-stall herds.

Our objective was to describe the variation in lying behavior of dairy cows on tie-stall farms and to examine the relationship of lying time measures with the occurrence of lameness and hock and knee lesions at both the herd and the cow level.

\section{Materials and methods}

\subsection{Animals and housing}

Commercial tie-stall (TS) dairy farms with a mean herd size $( \pm \mathrm{SD})$ of 65.9 cows $( \pm 17.3$; range: 43 to 121$)$ and mean annual milk yield of $9570 \mathrm{~L}$ ( $\pm 875 \mathrm{~L}$; range: 7511 to
$11,870 \mathrm{~L}$ ) in Ontario (ON: $n=40$ ) and Quebec (QC: $n=60$ ) were visited between January and December 2011 as part of a larger study examining dairy cow longevity. The farms visited had to be enrolled in a milk recording scheme, have the ability to identify and match cows to their milk records, and have a majority of Holstein cows, with a mean milk production above $7000 \mathrm{~L} / \mathrm{cow} /$ year. Letters were sent to farms meeting these criteria, inviting them to participate in the study. Those interested and willing to participate in the study were then contacted by telephone and interviewed to determine whether they met further study criteria, including; a herd size of at least 40 lactating cows and a milking system which had been in use for a minimum of one year. Furthermore, the herds were selected to have variation in average cow longevity as measured by the percentage of cows in third lactation or higher $(39.7 \pm 8.5 \%$, range $15-59 \%)$ and the annual farm turnover rate $(36.5 \pm 10.9 \%$, range $17-79 \%$ ).

On 99 farms the cows were milked twice a day, and three times a day on one farm. Mean stall length was $178.0 \mathrm{~cm}$ $(\mathrm{SD}=7.28$; range $=148.2$ to $194.2 \mathrm{~cm})$, mean stall width was $126.6 \mathrm{~cm}(\mathrm{SD}=7.90$; range $=102.9$ to $144.2 \mathrm{~cm})$ and mean chain length was $77.0 \mathrm{~cm}(\mathrm{SD}=17.70$; range $=47.8$ to $119.4 \mathrm{~cm}$ ). The cows had their tails tied on $43.3 \%$ of the farms, $71.1 \%$ of farms used trainers, and $69.6 \%$ of those trainers had electric power. Rubber mats formed the most common stall base type on $51 \%$ of farms, followed by geotextile mattresses on $45 \%$ of farms. Straw was used as bedding material in $94 \%$ of the farms.

\subsection{Data collection}

Each farm was visited twice at an interval of 5 to $10 \mathrm{~d}$ and data were collected on 40 lactating Holstein dairy cows from each herd (DIM (days in milk) (mean $\pm \mathrm{SD}=156.0 \pm 95.7$; range 4-735; parity range: 1 to 12 with $36 \%$ primiparous cows)), resulting in data from a total of 3649 cows.

To record the time the cows spent lying down, electronic data loggers (HOBO Pendant G Acceleration Data Loggers, Onset Computer Corporation, Pocasset, MA, USA) were attached to the hind leg of each cow using Vet-Wrap (CoFlex, Andover Coated products Inc., Salisbury, MA, USA), and programmed to record the position of the cow (lying or standing) at 1-min intervals for 4 consecutive days (Vasseur et al., 2012). Recording was set to begin at 23:50 h on the day of the first farm visit. During the second farm visit, all of the data loggers were removed and the data was downloaded. Excel macros (Microsoft corp., Redmond, WA, USA) were used to calculate, for each cow, the total duration of lying time, lying bout frequency, and the mean duration of lying bouts over $4-d$.

\subsubsection{Lameness scores}

During farm visits, the 40 focal cows on each farm were tested. Each test was filmed, and the video was later watched twice by the same assessor to determine lameness. Twenty percent of the videos $(n=800)$ were also scored a second time by one of two trained observers, to check for inter-observer repeatability (92.0\%). The method used to score the cows for lameness in the stall was 
Table 1

Description of lesion scores assigned to cows (Gibbons et al., 2012).

\begin{tabular}{|c|c|c|c|c|}
\hline & Score 0 & Score 1 & Score 2 & Score 3 \\
\hline Hock (tarsus) & $\begin{array}{l}\text { No swelling. No hair is } \\
\text { missing or broken hair }\end{array}$ & $\begin{array}{l}\text { Bald area on hock with } \\
\text { no swelling or swelling } \\
<1 \mathrm{~cm} \text { high }\end{array}$ & $\begin{array}{l}\text { Swelling, } 1-2.5 \mathrm{~cm} \\
\text { high, and/or broken } \\
\text { skin/scab on bald area }\end{array}$ & $\begin{array}{l}\text { Swelling, }>2.5 \mathrm{~cm} \text { high. } \\
\text { May have bald } \\
\text { area/broken skin/scab }\end{array}$ \\
\hline Knee (carpus) & $\begin{array}{l}\text { No swelling. No hair is } \\
\text { missing or slight hair } \\
\text { loss or broken hair }\end{array}$ & No swelling. Bald area & $\begin{array}{l}\text { Broken skin or scab } \\
\text { and/or swelling } \\
\text { (<2.5 cm high). May } \\
\text { have bald area }\end{array}$ & $\begin{array}{l}\text { Swelling } \geq 2.5 \mathrm{~cm} \text { high. } \\
\text { May have bald } \\
\text { area/lesion }\end{array}$ \\
\hline
\end{tabular}

developed by Leach et al. (2009) and adapted by Gibbons et al. (2014), who showed this stall lameness scoring method is strongly correlated with that obtained from gait scoring. Scoring involved observing the cows in the tiestall for four behaviors. Cows were identified as lame when two or more of the following behaviors were observed on the hind limbs: (1) edge (standing on the edge of the step when stationary, presumed to be done to relieve pressure on one part of the claw), (2) weight shift (assessed laterally: regular, repeated transfer of weight from one hoof to another), (3) rest (repeatedly avoiding putting full weight on one foot, and lifting it more than the other), (4) uneven (uneven weight bearing between feet when encouraged to move from side to side. This was demonstrated by a more rapid movement by one foot than the other or by an evident reluctance to bear weight on a particular foot).

\subsubsection{Lesion scoring}

Cows were scored for lesions on the tarsus joint (hock), and carpus joint (knee), according to the method described by Gibbons et al. (2012). A score of 0 to 3 was assigned for both the left and right legs (Table 1). There was never more than two observers per farm and each observer would assess the same lesion type on all cows on a farm.

\subsection{Data and statistical analysis}

Due to the presence of some unusually long lactations, cows with DIM greater than $310 \mathrm{~d}$ were excluded from the analysis. Medians were calculated for daily duration of lying time, daily lying bout frequency, and daily mean lying bout duration for each cow using the data from the four sampling days (Vasseur et al., 2012). In addition, medians for these variables were also calculated for each herd. Cows were scored as (1) lame if they scored positive for two or more of the behaviors (Gibbons et al., 2014), (2) having an obvious hock lesion if they had a hock lesion score of 2 or 3 on at least one leg, and (3) having an obvious knee lesion if they had a knee lesion score of 2 or 3 on at least one leg. Cows were excluded if there was a missing value for one leg. The prevalence (\% cows) of lameness, obvious hock and knee injuries, as well as the median DIM and parity were calculated for each farm.

Distributions of some of the variables showed a positive skew and so a log transformation was used. However, the transformation did not change the pattern of significance and so we report on the results using untransformed data. Pearson correlations were calculated between the measures of lying time for each cow and her DIM and parity. Logistic regression was used to examine the relationship at the cow level between the occurrence ( 0 or 1 ) of lameness, hock injuries and knee injuries and the measures of lying time, using a separate model for each type of lesion. The parity and DIM was included in the model, since these could have an impact on lying time (Vasseur et al., 2012). We examined the sensitivity (\% of lame or injured cows correctly identified) and the specificity (\% of non-lame and non-injured cows correctly identified) using the median lying time $(12.5 \mathrm{~h} / \mathrm{d})$ as a threshold.

Pearson correlations were calculated between the median measures of lying time on the farm and the farm prevalence of lameness, hock and knee injuries (expressed as \% cows), the median DIM, parity, the annual milk yield and herd size. Stepwise regression was used to assess the relationship at the herd level between the prevalence of lameness and leg lesions and the median values for the lying time variables, with the median parity and median DIM for the farm included in the models. Canonical discrimination with stepwise selection (using PROC DISCRIM of SAS) was used to find the optimum combination of measures of lying time that could best distinguish farms that were at or above the median for the percent of cows that were either lame or had a leg lesion from farms that were below the median, and we assessed the sensitivity and specificity of various threshold measures of lying time (between 12 and $13 \mathrm{~h} / \mathrm{d}$ ).

\section{Results}

\subsection{Cow level analyses}

Table 2 shows the daily duration of lying down, the daily frequency of lying bouts and mean duration of lying bouts for individual cows, and Fig. 1 shows the percent distribution of daily duration of lying time and the daily frequency of lying bouts for the 3649 individual cows. There were large differences between cows in all three measures of lying down. There were moderate correlations (all: $P<0.0001, n=3584$ ) between DIM and daily duration of lying down $\left(r_{p}=0.28\right)$ and mean bout duration $\left(r_{p}=0.22\right)$, with a low correlation with lying bout frequency $\left(r_{p}=-0.09\right)$. There were moderate correlations between parity (all: $P<0.001, n=3636$ ) and frequency of lying bouts $\left(r_{p}=-0.23\right)$ and mean bout duration $\left(r_{p}=0.17\right)$ and a low correlation with daily duration of lying down $\left(r_{p}=-0.09\right)$ (Figs. 2 and 3).

Overall $24.2 \%$ of the cows were scored as being lame, $56.3 \%$ had an obvious hock lesion, and $42.7 \%$ had an obvious knee lesion. There was no relationship $(P>0.10)$ between being lame and daily duration of lying time (mean $\pm S E$ : 
Table 2

Percentiles for median daily duration of time spent lying down (h), median daily frequency of bouts of lying down, and mean duration of bouts of lying down for individual cows and individual tie-stall farms.

\begin{tabular}{|c|c|c|c|c|c|}
\hline & 1 st \%o & 25 th \% & 50 th \% & 75th \% & 99th \%。 \\
\hline \multicolumn{6}{|l|}{ Individual cows $(n=3649)$} \\
\hline Daily duration (h) & 6.3 & 10.9 & 12.5 & 14.0 & 17.9 \\
\hline Daily bout frequency & 4.0 & 9.0 & 11.0 & 13.5 & 23.5 \\
\hline Average bout duration (min) & 28.4 & 56.6 & 68.3 & 83.8 & 150.0 \\
\hline \multicolumn{6}{|l|}{ Individual farms $(n=100)$} \\
\hline Daily duration (h) & 10.0 & 11.9 & 12.5 & 13.1 & 15.0 \\
\hline Daily bout frequency & 8.4 & 10.0 & 11.0 & 11.5 & 13.8 \\
\hline Median average bout duration (min) & 53.4 & 64.1 & 68.2 & 74.2 & 89.7 \\
\hline
\end{tabular}

non-lame $=12.44 \pm 0.04 \mathrm{~h}$, lame $=12.30 \pm 0.09 \mathrm{~h}$ ), the frequency of lying bouts or mean bout duration. Cows with hock lesions had a lower daily duration of lying time than those without (mean \pm SE: no lesion $=12.79 \pm 0.06 \mathrm{~h}$, lesion $\left.=12.21 \pm 0.06 \mathrm{~h} ; \chi^{2}=33.86, P<0.001\right)$ but did not differ in the frequency of lying bouts or mean bout duration $(P>0.10)$. Cows with knee injuries had a lower daily duration of lying time than those without (mean $\pm S E$ : no lesion $=12.54 \pm 0.05 \mathrm{~h}$, lesion $=12.25 \pm 0.06 \mathrm{~h} ; \chi^{2}=4.06$, $P=0.04$ ) but did not differ in the frequency of lying bouts or mean bout duration $(P>0.10)$. Over half $(53.4 \%)$ of the cows without hock or knee lesions had daily durations of lying down more than $12.5 \mathrm{~h}$ while $56.2 \%$ of cows with a hock or knee lesion lay down for less than $12.5 \mathrm{~h} / \mathrm{d}$. Using $12.5 \mathrm{~h} / \mathrm{d}$ as a threshold would correctly classify only $55.4 \%$ of cows as having a leg lesion or as not having a leg lesion.
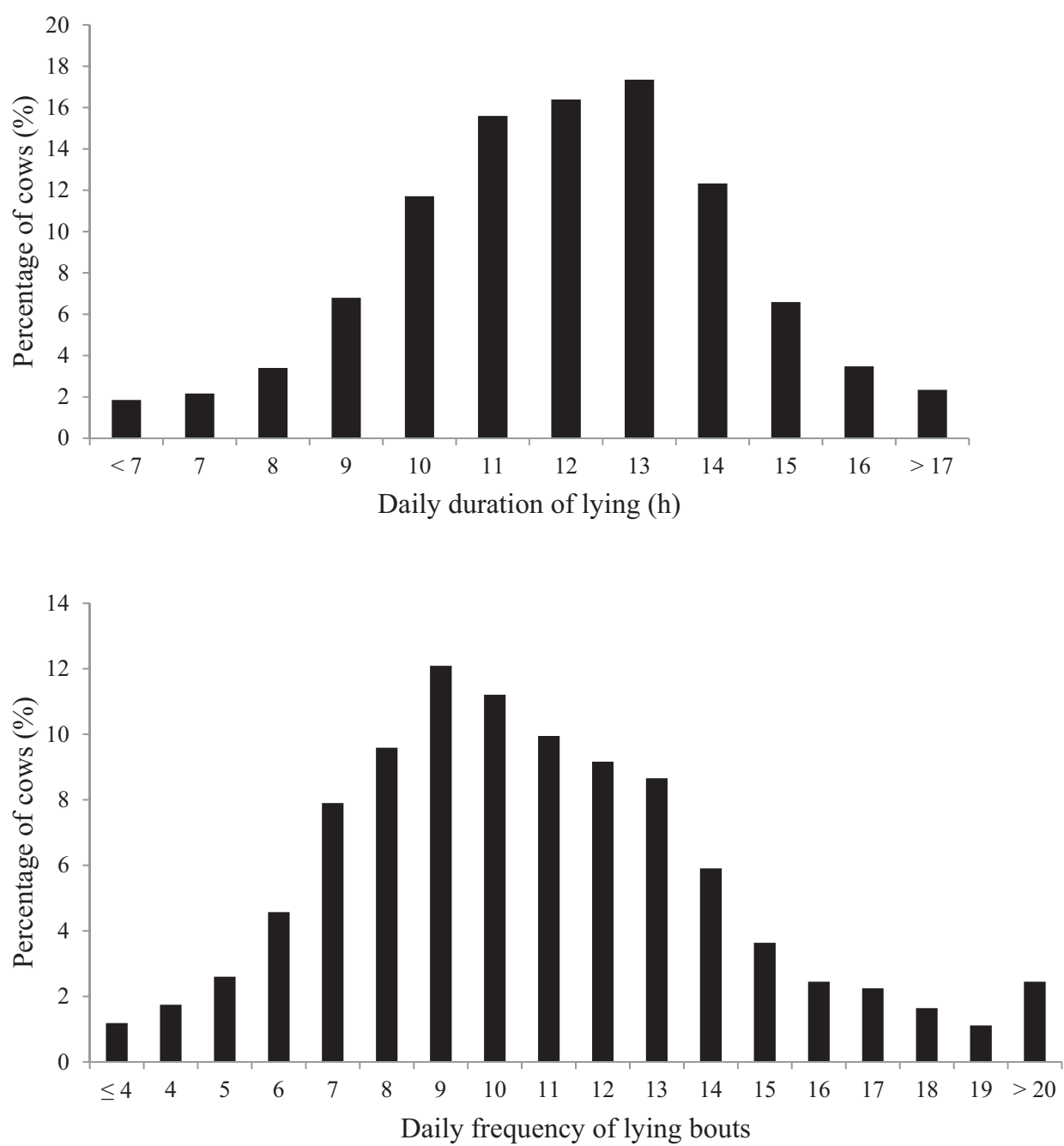

Fig. 1. Percent cows with various median daily duration of lying down (upper panel) and median daily frequency of lying bouts (lower panel). 

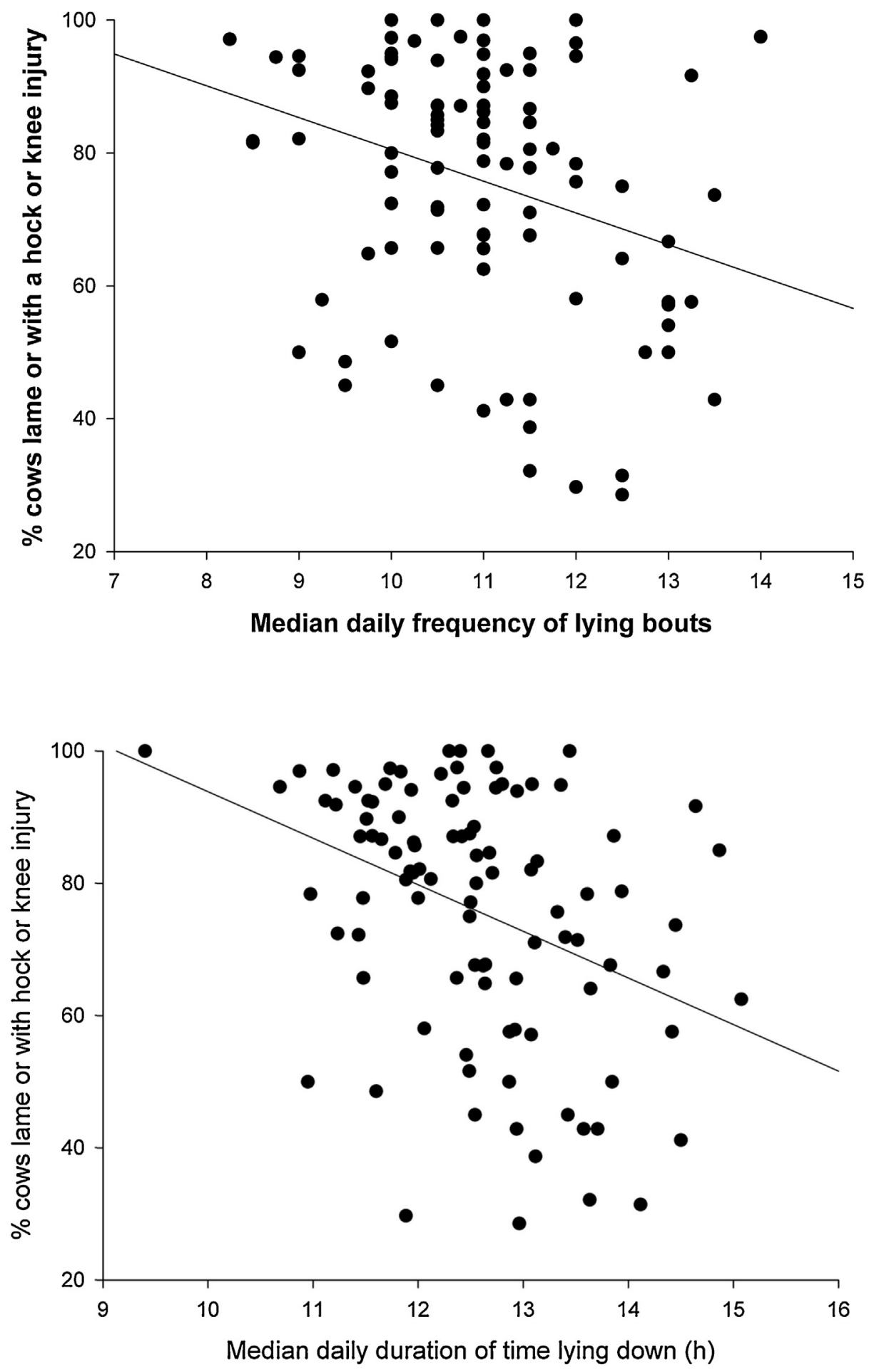

Fig. 2. The percentage of cows that were either lame or had a hock or knee lesion on each farm and the median daily frequency of lying bouts (upper panel) and the median daily duration of lying time (lower panel). Each point represents a single farm.

\subsection{Herd level analyses}

Table 2 shows the daily duration of lying down, the daily frequency of lying bouts and mean duration of lying bouts for farms. The prevalence of the injuries varied across farms: lameness from 0 to 55.6\%, hock injuries from 6 to $94 \%$ and knee injuries from 0 to $89 \%$. The prevalences of lameness, hock injuries and knee injuries were highly inter-correlated across farms (lameness vs hock injuries $r_{p}=0.48$; lameness vs knee injuries $r_{p}=0.58$; hock injuries 


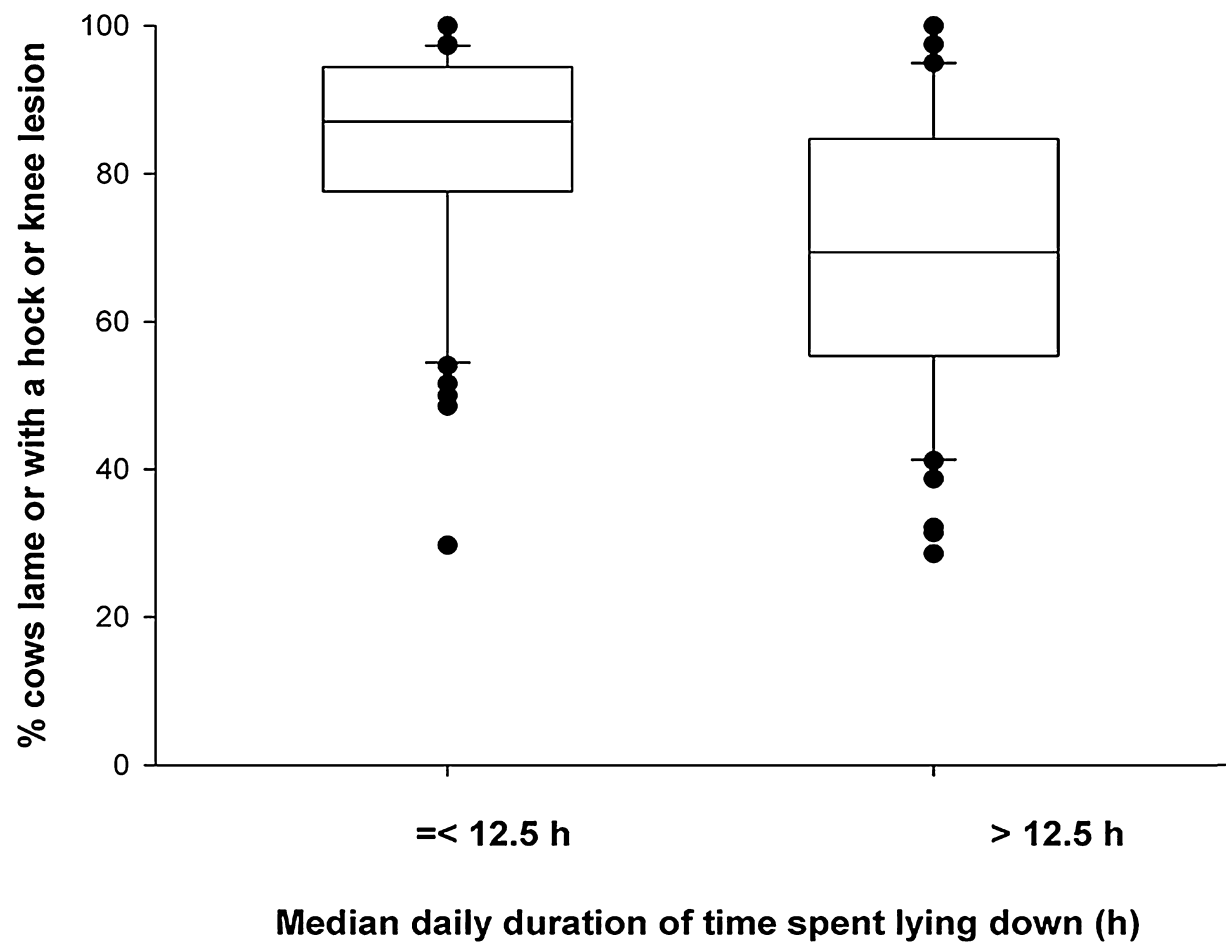

Fig. 3. Percent of cows that were lame or had a hock or knee lesion for farms that had a median duration of time spent lying down that was either equal to or less than $12.5 \mathrm{~h}$ or greater than $12.5 \mathrm{~h}$. The graph shows the 5 th, $25 \mathrm{th}, 50$ th (median), 75 th and 95 th percentiles and individual farms beyond the 5 th and 92 th percentiles.

vs knee injuries $r_{p}=0.67$; all: $\left.n=100, P<0.001\right)$. The prevalence of lameness and of injuries was not correlated with mean parity, DIM, herd size or annual milk production $(P>0.10)$.

Correlations between measures of lying time, prevalence of lesions and farm characteristics are shown in Table 3 . The daily duration of lying time was positively correlated with annual milk yield and mean DIM. The prevalence of lameness on a farm, hock injuries and knee injuries were negatively correlated with the median daily duration of lying time and the median frequency of lying bouts but not with mean bout duration. The results of the multiple regression showed that the percent of cows on a farm that had either a hock lesion, a knee lesion or were lame could be partially predicted (overall model: $r^{2}=0.17$, $P<0.001$ ) by mean daily duration of lying time (partial $\left.r^{2}=0.08, P=0.004\right)$, with a trend for the mean frequency of lying bouts to be included (partial $r^{2}=0.03, P=0.08$ ). A canonical discriminant function with canonical coefficients of 0.63 for mean daily duration of lying down, and of 0.54 for mean bout frequency could correctly identify $72 \%$ of the farms that were above the median for percent of cows with hock or knee injuries or being lame (linear discriminant function: constant $=-95.10$, daily duration $=11.39$, bout frequency $=4.83$ ) and $68 \%$ of the farms below the median (linear discriminant function: constant $=-106.95$, daily duration $=11.92$, bout frequency $=5.30$ ) (Wilks Lambda test $P=0.002$ ). Using simple thresholds between $12 \mathrm{~h}$ and $13 \mathrm{~h}$ for the daily duration of lying time alone could accurately classify over $60 \%$ of the farms as being above or below the median for the percent of cows that were lame or had a leg lesion (Table 4).

\section{Discussion}

We found wide variation both between individual cows and farms in the time that cows spend lying down. This large inter-cow variation in lying time was also reported by Ito et al. (2009) who found that lying times for individual cows in free-stall barns ranged from 4.2 to $19.5 \mathrm{~h} / \mathrm{d}$. The median lying time of $12.5 \mathrm{~h}$ is similar to the $13 \mathrm{~h}$ suggested as the amount of time lying down that cows are motivated to work for (Jensen et al., 2005). Some of the very large variation between cows was related to parity and stage of lactation agreeing with previous research (Norring et al., 2012; Vasseur et al., 2012). The daily duration of time spent lying down increased as DIM increased, mainly due to an increase in mean bout duration, while older cows had a reduced frequency of lying bouts than younger ones. The low values found for lying time for some cows (i.e. less than $4 \mathrm{~h} / \mathrm{d}$ ) is surprising given that lying down is a high priority activity for dairy cattle (Jensen et al., 2005; Munksgaard et al., 2005). Some cows may have been in estrus during the study, which could explain the low lying times. However, mean daily lying duration was calculated over four days, and behavioral expressions of estrus are unlikely to last that long (Sveberg et al., 2011). At the other extreme, over $2 \%$ of cows lay down for more than $17 \mathrm{~h} / \mathrm{d}$. To meet their nutritional requirements dairy cows in tie-stalls will spend approximately $4 \mathrm{~h} / \mathrm{d}$ eating (Haley et al., 2001; 


\section{Table 3}

Pearson correlations (and probability) between the median of the daily duration of time spent lying down, the frequency of bouts of lying down and the mean duration of bouts of lying down of 100 farms with the farm medians for herd size, annual milk yield, DIM, and parity, and the farm prevalence (\% cows) of lameness, hock injuries, and knee injuries and \% cows that are either lame or have a hock lesion, knee lesion.

\begin{tabular}{|c|c|c|c|}
\hline & Daily duration & Bout frequency & Mean bout duration \\
\hline Milk yield & $0.23(0.02)$ & $0.14(>0.10)$ & $0.06(>0.10)$ \\
\hline Herd size & $-0.11(>0.10)$ & $0.08(>0.10)$ & $-0.12(>0.10)$ \\
\hline DIM & $0.20(0.04)$ & $-0.04(>0.10)$ & $0.16(>0.10)$ \\
\hline Parity & $0.00(>0.10)$ & $-0.02(>0.10)$ & $0.04(>0.10)$ \\
\hline Hock lesions & $-0.35(0.003)$ & $-0.22(0.03)$ & $-0.08(>0.10)$ \\
\hline Knee lesions & $-0.28(0.004)$ & $-0.34(<0.001)$ & $0.10(>0.10)$ \\
\hline Lameness & $-0.27(0.006)$ & $-0.27(0.006)$ & $0.05(>0.10)$ \\
\hline Lameness or lesion & $-0.37(<0.001)$ & $-0.30(0.002)$ & $-0.02(>0.10)$ \\
\hline
\end{tabular}

Norring et al., 2012) and with other behavioral priorities such as drinking and with time taken for cows to be milked it is surprising that some cows spent so much time lying down.

At the cow level, we found no relationship between lameness and the measures of lying time, which is in contrast to what is most often reported for cows in free stalls (Blackie et al., 2011; Chapinal et al., 2009; Ito et al., 2010). This difference may reflect the fact that cows in tie-stalls do not need to walk or stand on hard floors to feed. Rubber mats and geotextile mattress were the most common stall base types and most farms used straw bedding in the stalls. This softer underfoot surface may allow lame cows in tiestalls to stand for longer, compared to cows in free-stall barns which usually have to walk and stand on concrete flooring. For cows in tie-stalls there was a clear relationship between lying time and hock and knee lesions, with the cows with lesions spending about 20-30 min less time lying down than cows without lesions. This corresponds with what was found in small scale experimental studies (Rushen et al., 2007). Despite this difference, measures of lying time do not appear very promising to help detect cows with lesions due to the large overlap in lying time between the groups with and without lesions. However, an alternative indicator of cows with and without lesions may be the time it takes for cows to transition from standing up to lying down and vice versa. Lame and injured cows may need more time to lie down and stand up compared to healthy cows and therefore the transition time should be investigated.

We also found a large variation between farms in the median daily duration of lying time, which ranged from $10.3 \mathrm{~h}$ to $14.4 \mathrm{~h}$. This is similar to the range of lying times previously reported (European Food Safety Authority, 2009). The Canadian Dairy Code of Practice recommends that stalls should be built to enable cows to lie down for at least $12 \mathrm{~h} / \mathrm{d}$ (Dairy Farmers of Canada, 2009) and the median duration of lying time for these farms met this goal. Some of the variation between farms is due to milk yield, with cows on the higher producing farms lying down for longer than cows on lower producing farms. This is the opposite from the results of Norring et al. (2012) who reported that high producing cows in tie-stall farms lay down for less time than low producing cows. Possible explanations for this contradictory finding could be sample size, cattle breed or stage of lactation as the findings from Norring et al. (2012) were based on a study of 29 Finnish Ayrshire cows in their 8th week of lactation. Some of the variation in lying times of the current study is due to the stage of lactation of the cows in the sample, with farms with cows more advanced in lactation having a longer duration of lying down than those earlier in lactation, similar to findings by Vasseur et al. (2012). In this study, lying time for cows on tie-stall farms was longer than that previously reported for commercial free-stall farms in North America (Ito et al., 2009). The difference is most likely due to extra time spent waiting by the milking parlor, and for social activities and moving around the free-stall barn.

We found stronger relationships between lameness, leg lesions and time spent lying down at the herd level. We found a low, but significant relationship between the prevalence of lameness and leg lesions and measures of lying time of the cows on the farm. On farms with a high prevalence of lameness or leg lesions, the cows on average spent less time lying down, and had fewer bouts of lying down than on farms with a lower prevalence. The results are consistent with other studies that suggest that short lying times may be a risk factor for increased lameness (Bell et al., 2009; Dippel et al., 2009). Simple measures of lying time appeared to have potential in helping to identify farms

Table 4

Percent of farms correctly identified as being above or below the median for the percent of cows that were either lame or had a hock or knee lesion based using thresholds for the median daily duration of time spent lying down.

\begin{tabular}{lll}
\hline $\begin{array}{l}\text { Threshold value for daily } \\
\text { duration of lying down }{ }^{1}(\mathrm{~h})\end{array}$ & $\begin{array}{l}\text { Farms above median for lesion } \\
\text { prevalence or lameness (\%) }\end{array}$ & $\begin{array}{l}\text { Farms below median for lesion } \\
\text { prevalence or lameness }(\%)\end{array}$ \\
\hline 12 & 46 & 80 \\
12.25 & 50 & 76 \\
12.5 & 66 & 66 \\
12.75 & 80 & 42 \\
13 & 84 & 63
\end{tabular}

${ }^{1}$ Farms that had a median daily duration of lying down that was above the threshold were judged to be at or below the median ( $81.8 \%$ ) for the \% of cows that were either lame, or had a hock or knee lesion. 
that do have a high prevalence of lameness and leg lesions. Simply adopting a threshold of $12.5 \mathrm{~h} / \mathrm{d}$ was able to identify over $65 \%$ of farms that were above the median for the prevalence of lameness and leg lesions. Previous research shows that the design and management of tie-stalls, such as size of stalls and bedding use, can greatly influence the time cows lay down (Haley et al., 2001; Zurbrigg et al., 2005; Rushen et al., 2007). Including such influences into the model may further improve our ability to use lying time to identify cows and farms most at risk of lameness or leg lesions.

The use of outcome-based measures to assess animal welfare on farm is becoming increasingly popular (Whay et al., 2003; European Food Safety Authority, 2012). Generally, the most common measures are health based since behavioral measures can often be time consuming and labor intensive and so are often avoided. With recent advances in technology lying behavior can be measured automatically with a high percentage of accuracy and therefore has good potential of being used to assess cow comfort. Lameness is a significant welfare problem in cattle, but the difficulties in detecting lame cows in tie-stalls may result in an under-appreciation of the seriousness of lameness in these types of barns. Use of automated measures of lying time may help improve our ability to detect lameness in these systems.

\section{Conclusions}

There are large differences between cows and between farms in the amount of time that cows lay down in tiestall barns. This variation is related to the occurrence of leg lesions and (to a lesser extent) lameness. With further refinement of the method and validation, automated measures of lying time have the potential to improve our ability to detect farms that have high levels of lameness and leg lesions, especially when used in conjunction with other factors (e.g. presence of bedding, type of stall surface etc.) known to affect lying time and the risk of injury.

\section{Conflict of interest statement}

None declared.

\section{Acknowledgements}

This study was funded by Agriculture and Agri-Food Canada and Dairy Farmers of Canada (Ottawa, Ontario, Canada) as part of the Dairy Science Cluster initiative, as well as FRQNT-Novalait-MAPAQ-AAC as part of the Partnership program for innovation in dairy production and transformation. We thank the collaborators Dan Weary, Nina Von Keyserlingk (University of British Columbia, Vancouver, British Columbia, Canada), Karin Orsel, Herman Barkema, Ed Pajor, Laura Solano, Guilherme Bond, Steve Mason (University of Calgary, Calgary, Alberta, Canada), David Kelton, Stephen LeBlanc, Trevor DeVries, Jessica Zaffino-Heyerhoff, Clemence Nash (University of Guelph, Guelph, Ontario, Canada), François Becotte (Université Laval, Quebec, Quebec, Canada) and Daniel Lefevbre (Valacta Inc., Sainte-Anne-de-Bellevue, Quebec, Canada).
We also gratefully acknowledge all dairy producers participants.

\section{References}

Bell, N.J., Bell, M.J., Knowles, T.G., Whay, H.R., Main, D.J., Webster, A.J.F., 2009. The development, implementation and testing of a lameness control programme based on HACCP principles and designed for heifers on dairy farms. Vet. J. 180, 178-188

Bielfeldt, J.C., Badertscher, R., Tölle, K.H., Krieter, J., 2005. Risk factors influencing lameness and claw disorders in dairy cows. Livest. Prod. Sci. 95, $265-271$.

Blackie, N., Amory, J., Bleach, E., Scaife, J., 2011. The effect of lameness on lying behaviour of zero grazed Holstein dairy cattle. Appl. Anim. Behav. Sci. 134, 85-91.

Chapinal, N., de Passillé, A.M., Weary, D.M., von Keyserlingk, M.A.G., Rushen, J., 2009. Using gait score, walking speed, and lying behavior to detect hoof lesions in dairy cows. J. Dairy Sci. 92, 4365-4374

Cramer, G., Lissemore, K.D., Guard, C.L., Leslie, K.E., Kelton, D.F., 2009. Herd-level risk factors for seven different foot lesions in Ontario Holstein cattle housed in tie stalls or free stalls. J. Dairy Sci. 92, 1404-1411.

Dairy Farmers of Canada, 2009. Code of Practices for the Care and Handling of Dairy Cattle. Dairy Farmers of Canada, Ottawa, ON.

Dippel, S., Dolezal, M., Brenninkmeyer, C., Brinkmann, J., March, S., Knierim, U., Winckler, C., 2009. Risk factors for lameness in cubicle housed Austrian Simmental dairy cows. Prev. Vet. Med. 90, 102-112.

Espejo, L.A., Endres, M.I., 2007. Herd-level risk factors for lameness in highproducing holstein cows housed in freestall barns. J. Dairy Sci. 90, 306-314.

European Food Safety Authority Panel on Animal Health and Welfare, 2009. Scientific report on the effects of farming systems on dairy cow welfare and disease. EFSA-Q-2006-113.

European Food Safety Authority Panel on Animal Health and Welfare, 2012. Scientific opinion on the use of animal-based measures to assess welfare of dairy cows. EFSA J. 10, 1-81, http://dx.doi.org/10.2903/ j.efsa.2012.2554.

Gibbons, J., Haley, D., Higginson-Cutler, J., Nash, C., Zaffino, J., Pellerin, D., Adam, S., Fournier, A., de Passille, A., Rushen, J., Vasseur, E., 2014. A comparison of two methods of assessing lameness prevalence in tie-stall herds. J. Dairy Sci. 97, 350-353.

Gibbons, J., Vasseur, E., Rushen, J., de Passillé, A.M., 2012. A training programme to ensure high repeatability of injury scoring of dairy cows. Anim. Welf. 21, 379-388.

Haley, D.B., de Passillé, A.M., Rushen, J., 2001. Assessing cow comfort: effects of two floor types and two tie stall designs on the behaviour of lactating dairy cows. Appl. Anim. Behav. Sci. 71, 105-117.

Ito, K., Weary, D.M., von Keyserlingk, M.A.G., 2009. Lying behavior: assessing within- and between-herd variation in free-stall-housed dairy cows. J. Dairy Sci. 92, 4412-4420.

Ito, K., von Keyserlingk, M.A.G., LeBlanc, S.J., Weary, D.M., 2010. Lying behavior as an indicator of lameness in dairy cows. J. Dairy Sci. 93, 3553-3560.

Jensen, M.B., Pedersen, L.J., Munksgaard, L., 2005. The effect of reward duration on demand functions for rest in dairy heifers and lying requirements as measured by demand functions. Appl. Anim. Behav. Sci. 90, 207-217

Leach, K.A., Dippel, S., Huber, J., March, S., Winckler, C., Whay, H.R., 2009. Assessing lameness in cows kept in tie-stalls. J. Dairy Sci. 92, 1567-1574.

Munksgaard, L., Jensen, M.B., Pedersen, L.J., Hansen, S.W., Matthews, L., 2005. Quantifying behavioural priorities-effects of time constraints on behaviour of dairy cows, Bos taurus. Appl. Anim. Behav. Sci. 92, 3-14.

Norring, M., Valros, A., Munksgaard, L., 2012. Milk yield affects time budget of dairy cows in tie-stalls. J. Dairy Sci. 95, 102-108.

Rushen, J., Haley, D., de Passille, A.M., 2007. Effect of softer flooring in tie stalls on resting behaviour and leg injuries of lactating cows. J. Dairy Sci. 90, 3647-3651.

Rushen, J., de Passille, A.M., von Keyserlingk, M.A.G., Weary, D.M., 2008. The Welfare of Cattle. Springer, Dordrecht, The Netherlands.

Rushen, J., Chapinal, N., de Passillé, A.M., 2012. Automated monitoring of behavioural-based animal welfare indicators. Anim. Welf. 21, 339-350.

Sveberg, G., Refsdal, A.O., Erhard, H.W., Kommisrud, E., Aldrin, M., Tvete, I.F., Buckley, F., Waldmann, A., Ropstad, E., 2011. Behavior of lactating Holstein-Friesian cows during spontaneous cycles of estrus. J. Dairy Sci. 94, 1289-1301. 
Vasseur, E., Rushen, J., Haley, D., de Passillé, A.M., 2012. Sampling cows to assess lying time for on-farm animal welfare assessment. J. Dairy Sci. 95, 4968-4977

von Keyserlingk, M.A.G., Barrientos, A., Ito, K., Galo, E., Weary, D.M., 2012. Benchmarking cow comfort on North American freestall dairies: lameness, leg injuries, lying time, facility design, and management for high-producing Holstein dairy cows. J. Dairy Sci. 95, 7399-7408.

von Keyserlingk, M.A.G., Rushen, J., de Passille, A.M.B., Weary, D.M., 2009. Invited review: the welfare of dairy cattle-key concepts and the role of science. J. Dairy Sci. 92, 4101-4111.

Weary, D.M., Taszkun, I., 2000. Hock lesions and free-stall design. J. Dairy Sci. 83, 697-702.
Whay, H.R., Main, D.C.J., Webster, A.J.F., Green, L.E., 2003. Assessment of the welfare of dairy cattle using animal-based measurements: direct observations and investigation of farm records. Vet. Rec. 153, 197-202.

Zaffino Heyerhoff, J.C., LeBlanc, S., DeVries, T., Nash, C., Gibbons, J., Orsel, K., Barkema, H., Solano, L., Rushen, J., de Passille, A.M., Haley, D. 2014. Prevalence of, and factors associated with, hock, knee, and neck injuries on dairy cows in free-stall housing in Canada. J. Dairy Sci. 97, $173-184$.

Zurbrigg, K., Kelton, D., Anderson, N., Millman, S., 2005. Tie-stall design and its relationship to lameness, lesion, and cleanliness on 317 Ontario dairy farms. J. Dairy Sci. 88, 3201-3210 